\title{
Kinetic and isothermal adsorption properties of strontium and cesium ions by zeolitic materials synthesized from Jeju volcanic rocks
}

\author{
Min-Gyu Lee ${ }^{1}$, Sang-Kyu Kam², Chang-Han $\mathrm{Le}^{3^{+}}$ \\ ${ }^{1}$ Department of Chemical Engineering, Pukyong National University, Busan 48547, Korea \\ ${ }^{2}$ Department of Environmental Engineering, Jeju National University, Jeju 63243, Korea \\ ${ }^{3}$ Department of Environmental Administration, Catholic University of Pusan, Busan 46252, Korea
}

\begin{abstract}
The study focused on the removal of Sr and Cs ions in aqueous solutions by zeolitic materials synthesized from Jeju volcanic rocks using a fusion/hydrothermal method. The synthesis of the zeolitic materials was carried out using the fusion/hydrothermal method to reduce crystallization time. Morphological structures of the zeolitic materials could be confirmed to be the Na-A zeolite structure and crystalline with the chamfered-edged structure. In the adsorption experiment, as the initial concentrations of the Sr and Cs ions increased, it took longer to reach adsorption equilibrium. The adsorption kinetics and isotherms of $\mathrm{Sr}$ and Cs ions were predicted well by the pseudo-2 ${ }^{\text {nd }}$-order and Langmuir isotherm models, respectively. The maximum adsorption capacities of $\mathrm{Sr}$ and Cs ions by the Langmuir isotherm model were $154.8 \mathrm{mg} / \mathrm{g}$ and $144.0 \mathrm{mg} / \mathrm{g}$, respectively. The zeolitic materials prepared in this study is considered as an effective adsorbent for removing $\mathrm{Sr}$ and $\mathrm{Cs}$ ions in aqueous solutions.
\end{abstract}

Keywords: Adsorption, Cesium, Strontium, Volcanic rock, Zeolitic material

\section{Introduction}

Due to the nuclear power plant accidents in Fukushima (2011) and in Chernobyl (1986) a large amount of radioactive materials such as ${ }^{137} \mathrm{Sr}$ and ${ }^{90} \mathrm{Cs}$ ions are entering the water environment and destroying the aquatic ecosystem [1]. They have a long half-life and high solubility in water, so it is known that they remain for a long time. When the cells of the body bind to Sr and Cs ions, they can cause many kinds of diseases such as leukemia and skin cancer [2]. Several methods for example adsorption [3], solvent extraction [4], and chemical precipitation [5] have been proposed as treatment methods for wastewater solutions containing radioactive ions. The adsorption for removing their ions has attracted attention because it has advantages such as its convenient operation, non-pretreatment and low waste generation. Adsorbents such as natural minerals [6, 7], modified minerals [8, 9], natural zeolite [10, 11], and zeolitic materials [12, 13] have been applied to remove radioactive ions. The zeolitic materi-

This is an Open Access article distributed under the term of the Creative Commons Attribution Non-Commercial License (http://creativecommons.org/licenses/by-nc/3.0/) which permits unrestricted non-commercial use, distribution, and reproduction in any medium, provided the original work is properly cited.

Copyright (C) 2021 Korean Society of Environmental Engineers als has been widely used in metal ion adsorption because of their unique chemical and physical properties (thermal stability, cage structure, crystallinity, ion-exchange capacity, etc) [14]. The zeolitic materials generally have a higher adsorption capacity than the natural zeolites, however, it has the disadvantage of being expensive. Recently, many studies have focused on the search of inexpensive and efficient adsorbents, zeolitic materials, fabricated from various natural minerals and industrial wastes. The zeolitic materials such as Na-X, Na-A, Na-P1, and cancrinite were synthesized from the Italian Crotone Basin [15] and Jeju volcanic rocks [16] by the hydrothermal method. In addition, the zeolitic materials prepared from various natural minerals (i.e., bentonite, diatomite, kaolinite, and clay) and coal fly ash have been proposed [17-21].

The zeolitic materials have been efficiently used to remove the radioactive ions in aqueous solutions [10, 13, 22]. The adsorption mechanisms of $\mathrm{Sr}, \mathrm{Ca}, \mathrm{Ba}$, and $\mathrm{Cd}$ on the $\mathrm{Na}-\mathrm{A}$ zeolite were strongly influenced by the binding affinity of individual cations for the zeolite surface [23]. The maximum adsorption capacities of Co,

\author{
Received March 13, 2020 Accepted May 17, 2020 \\ ${ }^{\dagger}$ Corresponding author \\ Email: chlee@cup.ac.kr \\ Tel: +82-51-510-0624 \\ ORCID: 0000-0002-0641-1463
}


Cs, and Sr ions by Langmuir adsorption model on a natural zeolite (clinoptilolite) were $2.93 \mathrm{mg} / \mathrm{g}, 49.0 \mathrm{mg} / \mathrm{g}$, and $9.8 \mathrm{mg} / \mathrm{g}$, respectively [10]. The removal performance of $\mathrm{Cs}$ and $\mathrm{Sr}$ ions by a synthetic Na-A zeolite (commercial product) showed that the equilibrium data was well estimated by the Langmuir model more than the Freundlich model. The maximum adsorption capacities of the Cs and Sr ions were $90.7 \mathrm{mg} / \mathrm{g}$ and $69 \mathrm{mg} / \mathrm{g}$, respectively [13]. The Na-P1 zeolite prepared from Jeju volcanic rocks has the $\mathrm{Sr}$ adsorption capacity of $57.0 \mathrm{mg} / \mathrm{g}$ [22]. On the other hand, we were able to synthesize zeolitic materials with coal fly ash via a fusion/hydrothermal method [21], and the synthesized the zeolitic materials showed high adsorption capacities of $156.4 \mathrm{mg} / \mathrm{g}$ for $\mathrm{Sr}$ ion.

Previous studies have been many cases in which the removal of $\mathrm{Sr}$ and $\mathrm{Cs}$ ions was evaluated using a zeolite material. However, there have been very few cases where volcanic rocks were synthesized with zeolite materials to remove $\mathrm{Sr}$ and $\mathrm{Cs}$ ions. Therefore, the aims of this study are to synthesize zeolitic materials (Z-S1) from Jeju volcanic rocks in Korea by the fusion/hydrothermal reaction, and to study the adsorption kinetic and equilibrium properties for $\mathrm{Sr}$ and Cs ions by the Z-S1. To do this, the effects of different parameters for example initial concentration, contact time, $\mathrm{pH}$, and temperature were evaluated through batch experiments. The kinetic data was evaluated by applying it to the pseudo- $2^{\text {nd }}$ order and pseudo- $1^{\text {st }}$ order rate models. The results of adsorption equilibrium experiments were modeled by applying isotherms of Dubinin-Radushkevitch (DR), Freundlich, and Langmuir. In addition, the thermodynamic parameters were calculated.

\section{Material and Methods}

\subsection{Synthesis of Zeolitic Materials}

Jeju volcanic rocks were collected and crushed from the scoria mine in Hanrim-eup, Jeju Island. The samples sieved by 0.425 $\mathrm{mm}$ or less were dried at $110^{\circ} \mathrm{C}$ for $24 \mathrm{~h}$ and then used in the synthesis of zeolitic materials. The synthesis of the zeolitic materials was carried out using the fusion/hydrothermal method which is the same procedure as the previous study [24]. The molar ratio of $\mathrm{SiO}_{2} / \mathrm{Al}_{2} \mathrm{O}_{3}$ was fixed to 2.5 , and then the mixture adjusted to have a $\mathrm{NaOH} / \mathrm{Jeju}$ volcanic rocks ratio of 1.8 was fused at $550^{\circ} \mathrm{C}$ for $1 \mathrm{~h}$. The fused sample was aged at $30^{\circ} \mathrm{C}$ for $5 \mathrm{~h}$ and crystallized at $90^{\circ} \mathrm{C}$ for $5 \mathrm{~h}$ while stirring in aqueous solutions to prepare the zeolitic materials. The prepared zeolitic materials were washed several times with deionized water. They dried at $105^{\circ} \mathrm{C}$ for 2 $\mathrm{h}$ and pulverized to a size of 170 mesh or more.

\subsection{Adsorption Experiments for $\mathrm{Sr}$ and $\mathrm{Cs}$ lons}

The experiment was carried out batch wise. $500 \mathrm{~mL}$ of $\mathrm{Sr}$ and Cs ions solutions and $0.1 \mathrm{~g}$ of zeolite were placed in a 1,000 $\mathrm{mL}$ Erlenmeyer flask and stirred at $180 \mathrm{rpm}$ using a horizontal shaker (Johnsam, JS-FS-2500). Initial concentrations of Sr and Cs ions were adjusted at the range of $20-100 \mathrm{mg} / \mathrm{L}$ and 10 $-100 \mathrm{mg} / \mathrm{L}$, respectively. $2.0 \mathrm{~mL}$ of the sample was taken at regular intervals and treated with a centrifugal machine (Eppendorf, centrifuge 5415c) for $10 \mathrm{~min}$ at $10,000 \mathrm{rpm}$ simultaneously. After centrifugation, the supernatant was filtered and then the Sr and Cs ions concentrations were analyzed. The $\mathrm{Sr}$ and $\mathrm{Cs}$ ions concentrations were measured by an atomic absorption spectrophotometer (Shinmadzu, AA-7,000). The $\mathrm{pH}$ in the solutions was adjusted using $0.01 \mathrm{M} \mathrm{NaOH}$ and $0.01 \mathrm{M} \mathrm{HCl}$ with a pH meter (Orion, 420A). The samples morphologies were characterized using a scanning electron microscopy (SEM, Hitachi S-4200). The characterization of the samples was identified using an X-Ray diffractometer with a $\mathrm{Cu} \mathrm{K} \alpha$ radiation of $=1.54 \AA$ (XRD, D8 Advance, Bruker AXS). The acceleration current and voltage of XRD were set to $40 \mathrm{~mA}$ and $40 \mathrm{kV}$, respectively. Diffraction angle of $2 \theta$ in the range from 5 to $50^{\circ}$ in $0.02^{\circ}$ steps was scanned.

XRD patterns were identified by searching the International Centre for Diffraction Data (ICDD) powder diffraction file database using Joint Committee on Powder Diffraction Standards (JCPDS) files.

The Sr and Cs ions adsorption capacity adsorbed by the Z-S1 were calculated as follows:

$$
q_{t}=\frac{\left(C_{0}-C_{t}\right) V}{m}
$$

where $\mathrm{q}_{\mathrm{t}}$ is the adsorption capacity $\left(\mathrm{mg} / \mathrm{g}\right.$ ) at time $\mathrm{t}, \mathrm{C}_{0}$ is the initial concentration $(\mathrm{mg} / \mathrm{L}), \mathrm{C}_{\mathrm{t}}$ is the concentration $(\mathrm{mg} / \mathrm{L})$ at time $\mathrm{t}, \mathrm{V}$ is the volume (L) of solutions, and $\mathrm{m}$ is the amount $(\mathrm{g})$ of the Z-S1 used.

\section{Results and Discussion}

\subsection{Characterization of Zeolitic Materials}

Fig. 1 shows the XRD patterns of Jeju volcanic rocks, and the zeolitic materials (Z-S1) synthesized with the Jeju volcanic rocks. Jeju volcanic rocks mostly consist of quartz and mullite as shown in Fig. 1(a). The main XRD peaks of the Z-S1 are observed at the $2 \theta(\mathrm{CuK} \alpha / \mathrm{deg})$ values of 7.18, 23.96, 27.08 and 29.91 as seen in Fig. 1(b), and they are consistent with the positions of major diffraction peaks of standard Na-A zeolite (Fig. 1 (c)). Thus, it

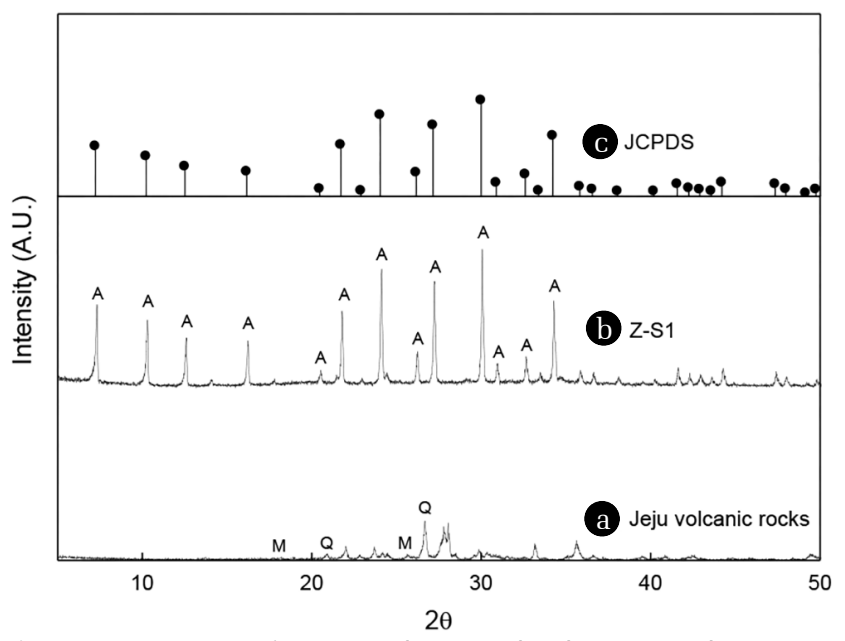

Fig. 1. XRD patterns of (a) Jeju volcanic rocks, (b) Z-S1, and (c) JCPDS card (No. 11-0590). 

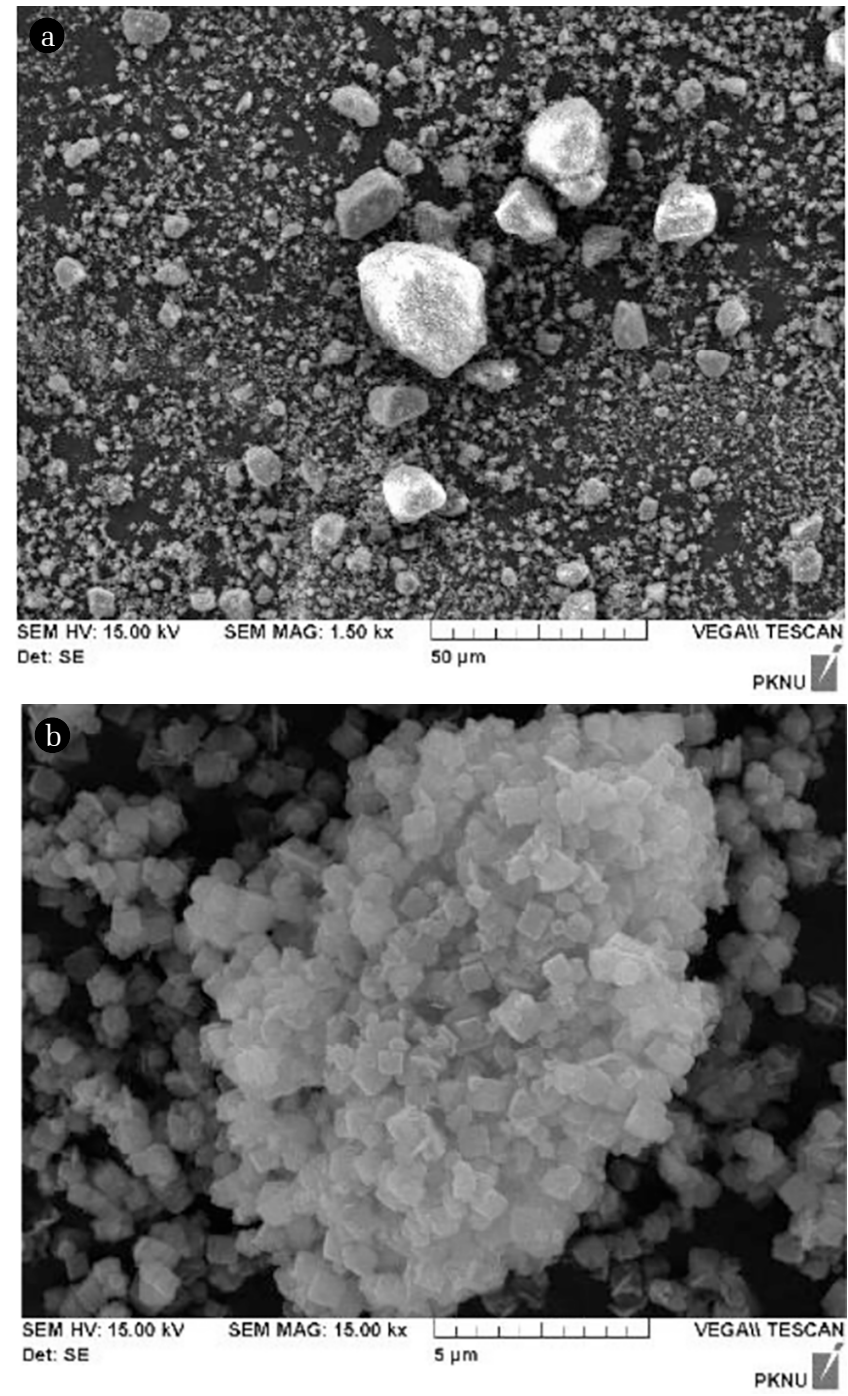

Fig. 2. SEM images of (a) the Jeju volcanic rocks and (b) the Z-S1.

can be identified as the Z-S1 has the morphological properties of Na-A zeolite. The XRD peaks of the Z-S1 match the standard XRD peaks for the Na-A zeolite $\left(\mathrm{Na}_{12} \mathrm{Al}_{12} \mathrm{Si}_{12} \mathrm{O}_{48} 27.4 \mathrm{H}_{2} \mathrm{O}\right)$ suggested by Treacy and Higgins [25]. SEM images of the Jeju volcanic rocks and the Z-S1 are presented in Fig. 2. The Jeju volcanic rocks have many amorphous particles in Fig. 2 (a). Fig. 2 (b) shows that the Z-S1 has lots of botryoidal cubic crystals with the formation of chamfered-edged. The structure of the cubic crystals corresponds to Na-A zeolite. These results showed that the Z-S1 was synthesized with Jeju volcanic rocks using the fusion/hydrothermal method. The crystals structures of the Z-S1 in this study and the zeolitic materials synthesized with fly ash by Lee et al. [21] and Tanaka et al. [26] were similar.

\subsection{Effect of $\mathrm{pH}$}

The effect of $\mathrm{pH}$ on the $\mathrm{Sr}$ and $\mathrm{Cs}$ ions adsorption capacities by the Z-S1 was examined in the $\mathrm{pH}$ range of $2-10$. The form of $\mathrm{Cs}$ and $\mathrm{Sr}$ species in aqueous solutions exist in the form of $\mathrm{Sr}^{2+}$

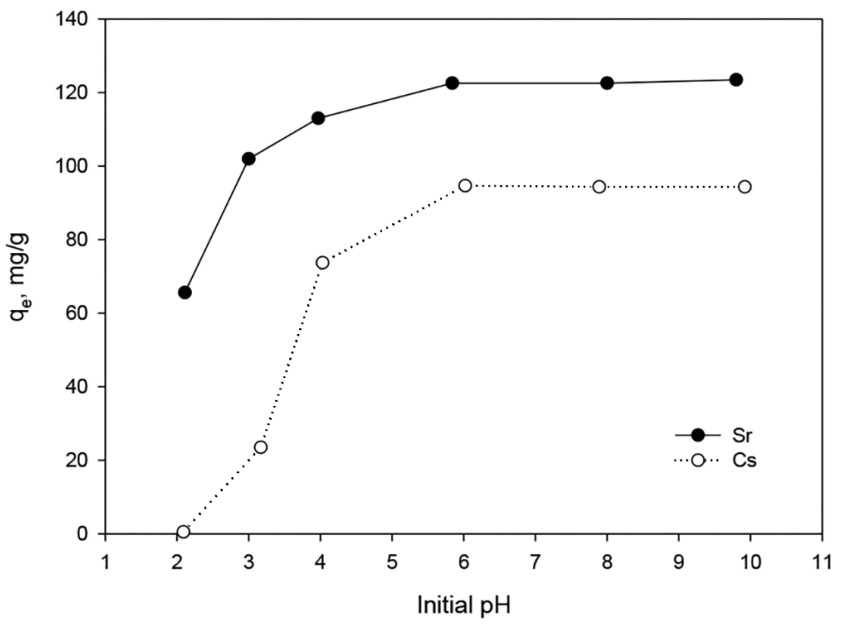

Fig. 3. Effect of initial $\mathrm{pH}$ on the $\mathrm{Sr}$ and $\mathrm{Cs}$ ions adsorption capacities by the Z-S1 (adsorbent $=0.2 \mathrm{~g} / \mathrm{L}$, temperature $=20^{\circ} \mathrm{C}$ ).

and $\mathrm{Cs}^{+}$at the $\mathrm{pH}$ range of 2-12 [27, 28]. As seen in Fig. 3, the $\mathrm{Cs}$ and $\mathrm{Sr}$ ions adsorption capacities by the Z-S1 are dependent on the solutions initial $\mathrm{pH}$. The $\mathrm{Sr}$ and Cs ions adsorption capacities at above pH 6 were almost constant as about 120 $\mathrm{mg} / \mathrm{g}$ and $90 \mathrm{mg} / \mathrm{g}$, respectively, however, they decreased rapidly at below $\mathrm{pH} 4$. In general, at a lower $\mathrm{pH} 4$, the hydrogen ions in the solution increases and the hydrogen ions compete with the $\mathrm{Sr}$ and $\mathrm{Cs}$ ions for the Z-S1 binding sites that the adsorption capacities of the $\mathrm{Sr}$ and $\mathrm{Cs}$ ions decreased.

The $\mathrm{pH}$ of the acids affects the zeolite structure. In the zeolite framework, the Si-O-Al is weaker than Si-O-Si and can easily be attached by $\mathrm{H}^{+}$ions affecting the zeolite structure [29]. The $\mathrm{Na}-\mathrm{A}$ zeolite structure with low $\mathrm{Si} / \mathrm{Al}$ ratios may collapse in the presence of acids with $\mathrm{pH}$ lower than 5.0. In fact, $\mathrm{pH}$ less than 5.0 is not recommended for zeolites [30]. Therefore, all subsequent experiments for adsorption kinetics and isotherms were examined at the initial $\mathrm{pH}$ of 6.0.

\subsection{Adsorption Kinetics}

The adsorption rate should be considered for the rational design of the adsorption process. In order to investigate the Sr and Cs ions adsorption kinetics by the Z-S1, the applicability of the pseudo- $1^{\text {st }}$ and the pseudo- $2^{\text {nd }}$ order models were evaluated from the experimental data.

The pseudo- $1^{\text {st }}$ order model is expressed as [10]:

$$
\ln \left(q_{e}-q_{t}\right)=\ln \left(q_{e}\right)-k_{1} t
$$

where $k_{1}$ is the pseudo- $1^{\text {st }}$ order rate constant $(1 / h)$, and $q_{e}$ is the adsorption capacity (mg/g) at equilibrium.

The pseudo- $2^{\text {nd }}$ order model is expressed as [13]:

$$
\frac{t}{q_{t}}=\frac{1}{k_{2} q_{e}^{2}}+\frac{1}{q_{e}} t
$$

where $k_{2}$ is the pseudo- $2^{\text {nd }}$ order rate constant $(\mathrm{g} / \mathrm{mg} \cdot \mathrm{h})$. 

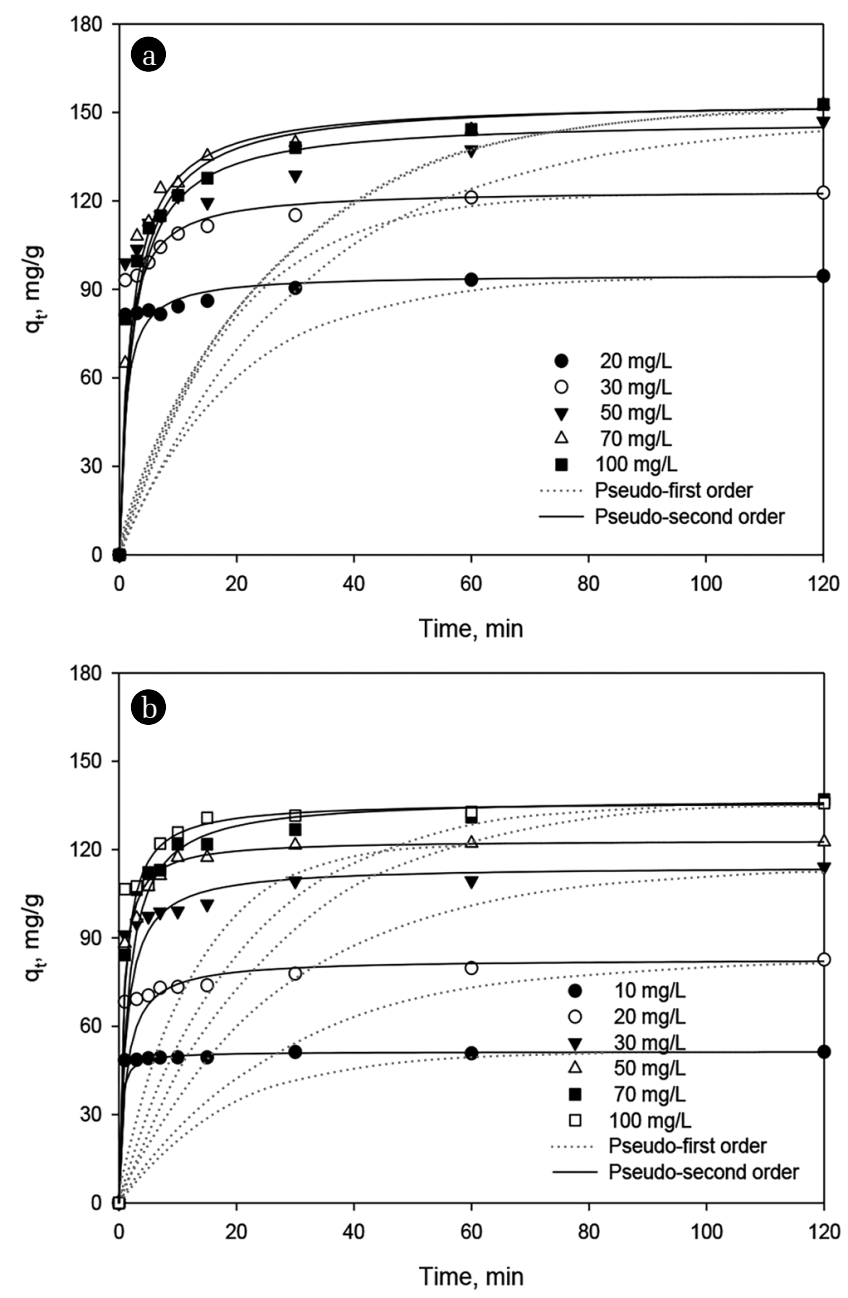

Fig. 4. Effect of contact time for the adsorption of (a) $\mathrm{Sr}$ and (b) Cs ions by the Z-S1 (adsorbent $=0.2 \mathrm{~g} / \mathrm{L}, \mathrm{pH}=6$, temperature $=293 \mathrm{~K})$.
The experimental and calculated values for the Sr and Cs ions adsorption kinetics by the Z-S1 are seen in Fig. 4(a) and 4(b), respectively. The Sr and Cs ions adsorption capacities by the Z-S1 increased sharply up to $10 \mathrm{~min}$, and it took longer to reach adsorption equilibrium for higher $\mathrm{Sr}$ and $\mathrm{Cs}$ ions initial concentrations, however, all cases reached equilibrium within 120 min. The rapid adsorption in the initial stage is because of the abundant binding sites on the pores of the zeolitic materials and it reaches equilibrium because of the occupation gradually on these binding sites as the contact time elapses. The kinetic parameters obtained by applying the experimental data to Eqs. (2) and (3) are summarized in Table 1. The decision coefficient $\left(r^{2}\right)$ of the pseudo- $1^{\text {st }}$ and pseudo- $2^{\text {nd }}$ order rate equations for the adsorption of Sr ions were $0.6652-0.8220$ and $0.9985-$ 0.9999 , respectively. The $\mathrm{r}^{2}$ for the adsorption of Cs ions were $0.4010-0.8075$ and $0.9995-1.0000$, respectively. As seen in Fig. 4 and Table 1, the adsorption capacity ( $\mathrm{q}_{\mathrm{e}, \exp }$ ) obtained from the experiment did not agree with the qe values estimated by the pseudo- $1^{\text {st }}$ order rate model, indicating that the pseudo- $1^{\text {st }}$ order model does not reproduce the $\mathrm{Sr}$ and $\mathrm{Cs}$ ions adsorption kinetics by the Z-S1. However, the $\mathrm{q}_{\mathrm{e}, \exp }$ are similar to the $\mathrm{q}_{\mathrm{e}}$ values calculated from the pseudo- $2^{\text {nd }}$ order rate model, and the $\mathrm{r}^{2}$ values are also very close to unity. From the results, the $\mathrm{Sr}$ and Cs ions adsorption process by the Z-S1 beads could be accurately explained by the pseudo- $2^{\text {nd }}$ order rate model rather than pseudo- $1^{\text {st }}$ order rate model.

Similar results could be found in the adsorption of various metal ions with volcanic rocks as an adsorbent [10,31], and also could be found in the adsorption of divalent ions by zeolites synthesized from volcanic rocks [22] and coal fly ash [21].

\subsection{Adsorption Isotherm and Thermodynamic Properties}

The three well known adsorption isotherm models such as Langmuir, Freundlich, and D-R isotherms were applied to investigate the adsorption equilibrium data.

The Langmuir model is expressed as [32]:

Table 1. Kinetic Parameters Calculated for The Sr and Cs lons Adsorption by The Z-S1

\begin{tabular}{|c|c|c|c|c|c|c|c|c|}
\hline \multirow[b]{2}{*}{ Ion } & \multirow[b]{2}{*}{$\begin{array}{c}\mathrm{C}_{0} \\
(\mathrm{mg} / \mathrm{L})\end{array}$} & \multirow[b]{2}{*}{$\begin{array}{c}q_{\mathbf{e}, \exp } \\
(\mathrm{mg} / \mathrm{g})\end{array}$} & \multicolumn{3}{|c|}{ Pseudo- ${ }^{\text {st }}$ order } & \multicolumn{3}{|c|}{ Pseudo-2 ${ }^{\text {nd }}$ order } \\
\hline & & & $\begin{array}{c}\mathbf{q e}_{(\mathrm{e}} \\
(\mathrm{g} / \mathrm{g})\end{array}$ & $\begin{array}{c}k_{1} \\
(1 / h)\end{array}$ & $\mathbf{r}^{2}$ & $\begin{array}{c}\mathrm{q}_{\mathrm{e}} \\
(\mathrm{mg} / \mathrm{g})\end{array}$ & $\begin{array}{c}k_{2} \\
\text { (mg/g.h) }\end{array}$ & $\mathbf{r}^{2}$ \\
\hline \multirow{5}{*}{$\mathrm{Sr}$} & 20 & 94.5 & 34.8 & 0.0501 & 0.7269 & 95.0 & 0.0109 & 0.9999 \\
\hline & 30 & 122.8 & 40.1 & 0.0548 & 0.8220 & 123.7 & 0.0065 & 0.9998 \\
\hline & 50 & 147.0 & 35.3 & 0.0313 & 0.6667 & 147.7 & 0.0030 & 0.9985 \\
\hline & 70 & 152.7 & 35.6 & 0.0382 & 0.6652 & 153.7 & 0.0032 & 0.9994 \\
\hline & 100 & 152.7 & 34.7 & 0.0386 & 0.7700 & 154.2 & 0.0027 & 0.9992 \\
\hline \multirow{6}{*}{ Cs } & 10 & 51.3 & 4.1 & 0.0557 & 0.4010 & 51.3 & 0.0686 & 1.0000 \\
\hline & 20 & 82.7 & 18.3 & 0.0358 & 0.5728 & 82.9 & 0.0105 & 0.9996 \\
\hline & 30 & 114.1 & 26.6 & 0.0366 & 0.5705 & 114.4 & 0.0074 & 0.9996 \\
\hline & 50 & 122.6 & 27.7 & 0.0807 & 0.8075 & 123.3 & 0.0128 & 1.0000 \\
\hline & 70 & 137.0 & 40.0 & 0.0378 & 0.6335 & 137.5 & 0.0049 & 0.9995 \\
\hline & 100 & 135.8 & 29.2 & 0.0483 & 0.6017 & 136.3 & 0.0084 & 0.9999 \\
\hline
\end{tabular}




$$
q_{e}=\frac{k_{L} q_{m} C_{e}}{1+k_{L} C_{e}}
$$

where $\mathrm{q}_{\mathrm{m}}$ is the maximum adsorption capacity $(\mathrm{mg} / \mathrm{g}), \mathrm{C}_{\mathrm{e}}$ is equilibrium concentration of adsorbate $(\mathrm{mg} / \mathrm{L}),\left(\mathrm{C}_{\mathrm{e}}\right)$ and $\mathrm{k}_{\mathrm{L}}$ is Langmuir constant (L/mg).

The Freundlich model is expressed as [33]:

$$
q_{e}=k_{F} C_{e}^{\frac{1}{n}}
$$

where $\mathrm{k}_{\mathrm{F}}$ is the Freundlich constant $\left((\mathrm{mg} / \mathrm{g})(\mathrm{L} / \mathrm{mg})^{1 / \mathrm{n}}\right)$, and $1 / \mathrm{n}$ is a constant indicating the adsorption strength.

The D-R isotherm is a Gaussian energy distribution at the surface, which is applied for describing the adsorption mechanism. The $\mathrm{D}-\mathrm{R}$ model is expressed as [34]:

$$
q_{e}=q_{m} \exp \left(-\beta \varepsilon_{p}^{2}\right)
$$

where $\beta$ is the Freundlich constant $\left(\mathrm{mol}^{2} / \mathrm{kJ}^{2}\right)$, and $\varepsilon_{\mathrm{p}}$ is a Polanyi potential $(\mathrm{kJ} / \mathrm{mol})$.

The $\varepsilon_{\mathrm{p}}$ is expressed as:

$$
\varepsilon_{p}=R T \ln \left(1+1 / C_{e}\right)
$$

where $\mathrm{R}$ is an ideal gas constant $(\mathrm{kJ} / \mathrm{mol} \cdot \mathrm{K})$, and $\mathrm{T}$ is an absolute temperature $(\mathrm{K})$.

The average adsorption energy $E(\mathrm{~kJ} / \mathrm{mol})$ is calculated as follows:

$$
E=\frac{1}{\sqrt{2 \beta}}
$$

As seen in Fig. 5, the experimental data and calculated values for the $\mathrm{Sr}$ and $\mathrm{Cs}$ ions adsorption isotherms by the Z-S1 at the solution temperatures of 293, 308, and $323 \mathrm{~K}$ were compared. The isotherm parameters and decision coefficients $\left(\mathrm{r}^{2}\right)$ obtained by fitting the experimental data to Eqs. (4) - (8) in Fig. 5 to the isotherm models are listed in Table 2. The $\mathrm{r}^{2}$ of the Langmuir, the Freundlich, and the D-R isotherms were 0.9984-0.9998, 0.8800-0.9754, and 0.9573-0.9868, respectively. As observed from Table 2 and Fig. 5, the equilibrium data fit the Langmuir adsorption isotherms well, more than Freundlich and the D-R isotherms.

As shown in Table 2, the maximum $\mathrm{Sr}$ and Cs ions adsorption capacities $\left(\mathrm{q}_{\mathrm{m}}\right)$ calculated from the Langmuir model increased from $154.8 \mathrm{mg} / \mathrm{g}$ to $175.1 \mathrm{mg} / \mathrm{g}$ and from 144.0 to $176.6 \mathrm{mg} / \mathrm{g}$ as the solution temperature increased from 293 to $323 \mathrm{~K}$, respectively. El-Kamash [13] also reported that the $\mathrm{q}_{\mathrm{m}}$ from the Langmuir model for the Sr and Cs ions adsorption by synthetic zeolite increased as the solution temperature increases. These results could be explained by the fact that the mobility of the $\mathrm{Sr}$ and $\mathrm{Cs}$ ions in an aqueous solution increases with temperature. Therefore, mass transfer with the $\mathrm{Sr}$ and $\mathrm{Cs}$ ions proceeds actively on the zeolite surface.
In the D-R isotherm, when the value of $E$ is in the range of $8-16 \mathrm{~kJ} / \mathrm{mol}$, the adsorption process should proceed with chemisorption or ion-exchange, while the value of $E$ is $8 \mathrm{~kJ} / \mathrm{mol}$ or less, the adsorption process occurs physically [35]. As shown in Table 2 , the $\mathrm{E}$ values of the $\mathrm{Sr}$ and $\mathrm{Cs}$ ions adsorption were between $10.4-12.7 \mathrm{~kJ} / \mathrm{mol}$ and $6.9-11.0 \mathrm{~kJ} / \mathrm{mol}$, respectively. Therefore, the adsorption of the Sr and Cs ions by the Z-S1 seems to be governed by the ion exchange or chemisorption. This result is consistent with that of Abusafa and Yücel [36].

Many studies have reported the adsorption capacities for metal ions from aqueous solutions by various adsorbents (Table S1). The adsorption capacities of $\mathrm{Sr}$ and $\mathrm{Cs}$ ions by natural zeolites such as clinoptilolite and bentonites, were $9.8 \mathrm{mg} / \mathrm{g}-28.4 \mathrm{mg} / \mathrm{g}$ and $49.0 \mathrm{mg} / \mathrm{g}$ - $73.1 \mathrm{mg} / \mathrm{g}$, respectively [10, 41, 42]. The adsorption capacities by a Na-A zeolite [21] synthesized from a fly ash were $156.4 \mathrm{mg} / \mathrm{g}$ for $\mathrm{Sr}$ ions and $101.5 \mathrm{mg} / \mathrm{g}$ for Cs ions, and the adsorption capacity of Sr ions by a Na-P1 zeolite [22] synthesized from Jeju volcanic rocks was $57 \mathrm{mg} / \mathrm{g}$. On the contrary, the $\mathrm{Sr}$ and $\mathrm{Cs}$ ions adsorption capacities by the Z-S1 in this study were $154.84 \mathrm{mg} / \mathrm{g}$ and $144.01 \mathrm{mg} / \mathrm{g}$, respectively, which were superior to other adsorbents reported in the literature.
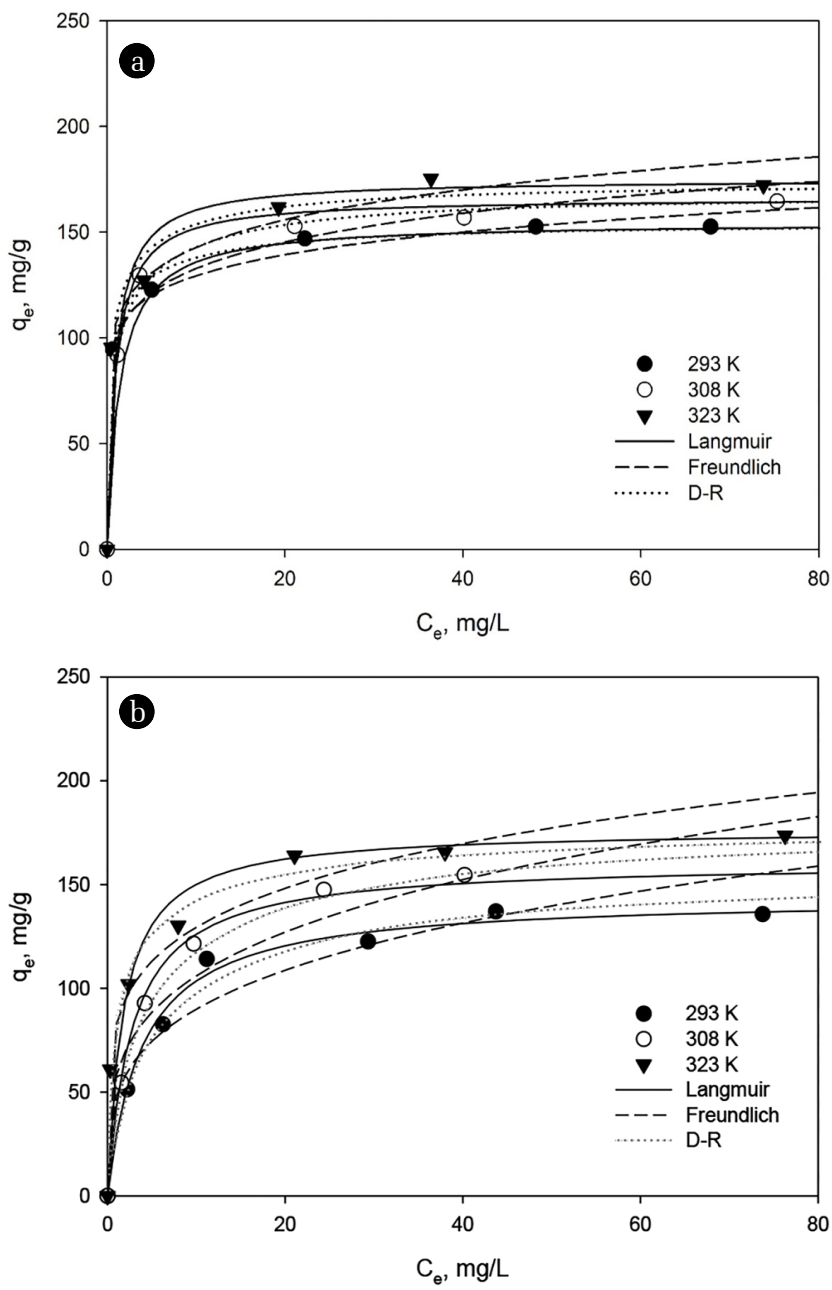

Fig. 5. Adsorption isotherms for (a) $\mathrm{Sr}$ and (b) Cs ions by the Z-S1 at different temperatures. 
Table 2. Isotherm Parameters for the Sr and Cs lons Adsorption by Z-S1

\begin{tabular}{|c|c|c|c|c|c|c|c|c|c|c|c|}
\hline \multirow[b]{2}{*}{ Ion } & \multirow[b]{2}{*}{$\begin{array}{c}T \\
(K)\end{array}$} & \multicolumn{3}{|c|}{ Langmuir } & \multicolumn{3}{|c|}{ Freundlich } & \multicolumn{4}{|c|}{ D-R } \\
\hline & & $\begin{array}{c}\mathbf{k}_{\mathrm{L}} \\
(\mathrm{L} / \mathbf{m g})\end{array}$ & $\begin{array}{c}\mathbf{q}_{\mathrm{m}} \\
(\mathrm{mg} / \mathrm{g})\end{array}$ & $\mathbf{r}^{2}$ & $\begin{array}{c}\mathbf{k}_{\mathrm{F}} \\
\mathrm{mg} / \mathrm{g} \cdot(\mathrm{L} / \mathrm{mg})^{1 / \mathbf{n}}\end{array}$ & $\mathbf{n}$ & $\mathbf{r}^{2}$ & $\underset{(\mathrm{mg} / \mathrm{g})}{\mathbf{q}_{\mathrm{m}}}$ & $\begin{array}{c}\boldsymbol{\beta} \\
\left.\left(\mathrm{mol}^{2} / \mathbf{k}\right)^{2}\right)\end{array}$ & $\begin{array}{c}E \\
(\mathrm{~kJ} / \mathrm{mol})\end{array}$ & $\mathbf{r}^{2}$ \\
\hline \multirow{3}{*}{$\mathrm{Sr}$} & 293 & 0.72 & 154.8 & 0.9998 & 101.2 & 9.36 & 0.9754 & 153.6 & 0.0035 & 11.9 & 0.9827 \\
\hline & 308 & 1.06 & 166.3 & 0.9995 & 98.5 & 7.70 & 0.8979 & 167.1 & 0.0046 & 10.4 & 0.9794 \\
\hline & 323 & 1.09 & 175.1 & 0.9994 & 106.7 & 7.91 & 0.9701 & 172.6 & 0.0031 & 12.7 & 0.9573 \\
\hline \multirow{3}{*}{ Cs } & 293 & 0.26 & 144.0 & 0.9984 & 47.9 & 3.66 & 0.8822 & 152.9 & 0.0106 & 6.9 & 0.9737 \\
\hline & 308 & 0.36 & 160.9 & 0.9995 & 58.0 & 3.82 & 0.8800 & 174.8 & 0.0086 & 7.6 & 0.9847 \\
\hline & 323 & 0.57 & 176.6 & 0.9992 & 82.5 & 5.11 & 0.9654 & 175.0 & 0.0041 & 11.0 & 0.9868 \\
\hline
\end{tabular}

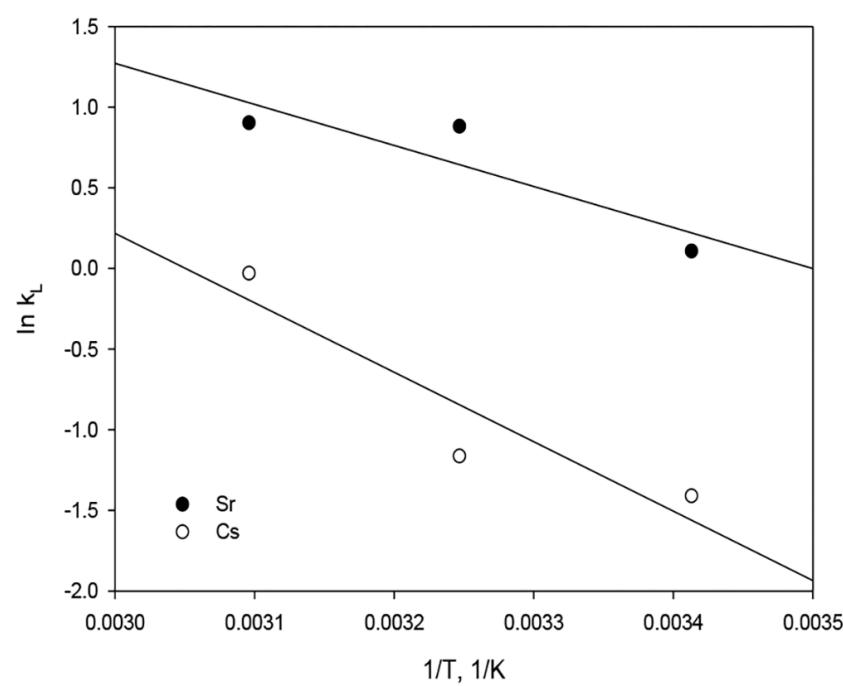

Fig. 6. Application of Van't Hoff plot for the adsorption of Sr and Cs ions by the Z-S1.

The thermodynamic parameters of change in Gibbs free energy $\left(\Delta \mathrm{G}^{\circ}\right)$, change in enthalpy $\left(\Delta \mathrm{H}^{\circ}\right)$ and change in entropy $\left(\Delta \mathrm{S}^{\circ}\right)$ can be calculated by the formula as follows [44]:

$$
\begin{gathered}
\triangle G^{\circ}=-R T \ln K_{L} \\
\ln K_{L}=\frac{\triangle S^{\circ}}{R}-\frac{\Delta H^{\circ}}{R T}
\end{gathered}
$$

where $\Delta \mathrm{G}^{\circ}(\mathrm{kJ} / \mathrm{mol}), \Delta \mathrm{H}^{\circ}(\mathrm{kJ} / \mathrm{mol})$ and $\Delta \mathrm{S}^{\circ}(\mathrm{J} / \mathrm{mol} \mathrm{K})$ are changes of Gibbs free energy, enthalpy and entropy, respectively. $\mathrm{T}$ is the absolute temperature $(\mathrm{K}), \mathrm{k}_{\mathrm{L}}$ is the Langmuir constant $(\mathrm{L} / \mathrm{mg})$, and $\mathrm{R}$ is the ideal gas constant $(\mathrm{J} / \mathrm{mol} \mathrm{K})$. The $\Delta \mathrm{G}^{\circ}$ at given temperatures were obtained from Eq. (9). The values of $\Delta \mathrm{H}^{\circ}$ and $\Delta \mathrm{S}^{\circ}$ in Eq. (10) were calculated by the slope and intercept on the plot of ln $k_{L}$ versus $1 / T$ (Fig. 6). These thermodynamic parameters for the $\mathrm{Sr}$ and $\mathrm{Cs}$ ions adsorption are given in Table S2. The $\Delta \mathrm{H}^{\circ}$ and $\Delta \mathrm{S}^{\circ}$ values for the $\mathrm{Sr}$ ions were $21.2 \mathrm{~kJ} / \mathrm{mol}$ and $74.0 \mathrm{~J} / \mathrm{mol} \cdot \mathrm{K}$, and $\mathrm{Cs}$ ions were $27.5 \mathrm{~kJ} / \mathrm{mol}$ and $109.2 \mathrm{~J} / \mathrm{mol} \cdot \mathrm{K}$, respectively. The $\Delta \mathrm{G}^{\circ}$ values for the $\mathrm{Sr}$ and $\mathrm{Cs}$ ions at $293-323 \mathrm{~K}$ were from -0.54 to $-2.76 \mathrm{~kJ} / \mathrm{mol}$ and from $-4.51 \mathrm{~kJ} / \mathrm{mol}$ to $-7.79 \mathrm{~kJ} / \mathrm{mol}$, respectively. Therefore, the $\Delta \mathrm{H}^{\circ}$ values for the $\mathrm{Sr}$ and Cs ions adsorption by the Z-S1 were positive because of the endothermic characteristic of the adsorption process. $\Delta S^{\circ}$ values were found to be positive due to the ion exchange of the $\mathrm{Sr}$ and $\mathrm{Cs}$ ions with more mobile ions, $\mathrm{Na}^{+}$ions [45, 46], present on the Z-S1. The $\Delta \mathrm{G}^{\circ}$ values for the $\mathrm{Sr}$ and $\mathrm{Cs}$ ions were negative at 293 - $323 \mathrm{~K}$ and the negative values indicate the feasibility and the spontaneous characteristic of the adsorption process by the Z-S1. These results were similar to those of Panayotova [47] who studied the removal of $\mathrm{Cu}$ ions from wastewater by use of zeolite.

\section{Conclusions}

The zeolitic materials, Z-S1, could be synthesized from Jeju volcanic rocks using a fusion/hydrothermal method. The morphological structures of the Z-S1 were confirmed to be highly crystalline with the chamfered-edged structure by a XRD and a SEM. Batch experiments were performed to study the adsorption kinetic and equilibrium properties for Sr and Cs ions by the Z-S1. The Sr and Cs ions adsorption kinetics were predicted well by the pseudo- $2^{\text {nd }}$ order rate equation rather than the pseudo- $1^{\text {st }}$ order rate equation. The Sr and Cs ions adsorption isotherms were fit by the Langmuir isotherm better than those of the Freundlich and the D-R isotherms at $293-323 \mathrm{~K}$. The maximum adsorption capacities by the Langmuir isotherm model were $154.8 \mathrm{mg} / \mathrm{g}$ for $\mathrm{Sr}$ ions and $144.0 \mathrm{mg} / \mathrm{g}$ for the Cs ions. The $\Delta \mathrm{H}^{\circ}$ and $\Delta \mathrm{S}^{\circ}$ values for the $\mathrm{Sr}$ and Cs ions were $21.2 \mathrm{~kJ} / \mathrm{mol}$ and $74.0 \mathrm{~J} / \mathrm{mol} \cdot \mathrm{K}$ and $27.5 \mathrm{~kJ} / \mathrm{mol}$ and $109.22 \mathrm{~J} / \mathrm{mol} \cdot \mathrm{K}$, respectively. The $\Delta \mathrm{G}^{\circ}$ values of the $\mathrm{Sr}$ and $\mathrm{Cs}$ ions at $293-323$ $\mathrm{K}$ were from -0.54 to $-2.76 \mathrm{~kJ} / \mathrm{mol}$ and from -4.51 to $-7.79 \mathrm{~kJ} / \mathrm{mol}$, respectively. The $\mathrm{Sr}$ and $\mathrm{Cs}$ ions adsorption processes by the Z-S1 synthesized from the Jeju volcanic rocks have an endothermic and spontaneous nature. Therefore, the Z-S1 prepared in this study is considered as effective adsorbents for removing $\mathrm{Sr}$ and $\mathrm{Cs}$ ions in aqueous solutions.

\section{Acknowledgment}

This research was supported by Basic Science Research Program through the National Research Foundation of Korea (NRF) funded by the Ministry of Education (NRF-2017R1D1A1B03030350).

\section{Author Contributions}

M.G.L. (Professor) conducted the adsorption experiments and wrote 
the manuscript; S.K.K. (Professor) supplied Jeju volcanic rocks and wrote the manuscript; C.H.L. (Professor) synthesized adsorbents and wrote the manuscript.

\section{References}

1. IAEA. Final Report of the International Mission on Remediation of Large Contaminated Areas Off-Site the Fukushima Dai-ichi, NE/NEFW/2011. 2011:7-15.

2. Munthali MW, Johan E, Aono H, Matsue N. $\mathrm{Cs}^{+}$and $\mathrm{Sr}^{2+}$ adsorption selectivity of zeolites in relation to radioactive decontamination. J. Asian Ceram. Soc. 2015;3:245-250.

3. Shawabkeh RA, Rockstraw DA, Bhada RK. Copper and strontium adsorption by a novel carbon material manufactured from pecan shells. Carbon 2002;40:781-786.

4. Kocherginsky NM, Zhang YK, Stucki JW, D2EHPA based strontium removal from strongly alkaline nuclear waste. Desalination 2002;144:267-272.

5. Sinha PK, Panicker PK, Amalraj RV. Treatment of radioactive liquid waste containing cesium by indigenously available synthetic zeolites: A comparative study. Waste Manage 1995;15: 149-157.

6. Siroux B, Beaucaire C, Tabarant M, Benedetti MF, Reiller PE. Adsorption of strontium and caesium onto an Na-MX80 bentonite: Experiments and building of a coherent thermodynamic modelling. Appl. Geochem. 2017;87:167-175.

7. Wissocq A, Beaucaire C, Latrille C. Application of the multi-site ion exchanger model to the sorption of $\mathrm{Sr}$ and $\mathrm{Cs}$ on natural clayey sandstone. Appl. Geochem. 2018;93:167-177.

8. Awual MR, Miyazaki Y, Taguchi T, Shiwaku H, Yaita T. Encapsulation of cesium from contaminated water with highly selective facial organic-inorganic mesoporous hybrid adsorbent. Chem. Eng. J. 2016;291:128-137.

9. Khandaker S, Toyohara Y, Saha GC, Awual MR, Kuba T. Devel opment of synthetic zeolites from bio-slag for cesium adsorption: Kinetic, isotherm and thermodynamic studies. J. Wat. Pro. Eng. 2020;33:101055.

10. Smiciklas I, Dimovic S, Plecas I, Removal of $\mathrm{Cs}^{1+}, \mathrm{Sr}^{2+}$ and $\mathrm{Co}^{2+}$ from aqueous solutions by adsorption on natural clinoptilolite, Appl. Clay Sci. 2007;35:139-144.

11. Munthali MW, Johan E, Aono H, Matsue N. $\mathrm{Cs}^{+}$and $\mathrm{Sr}^{2+}$ adsorption selectivity of zeolites in relation to radioactive decontamination. J. Asian Ceram. Soc. 2015;3:245-250.

12. Merceille A, Weinzaepfel E, Barré Y, Grandjean A. The sorption behaviour of synthetic sodium nonatitanate and zeolite A for removing radioactive strontium from aqueous wastes. Sep. Purif. Tech. 2012;96:81-88.

13. El-Kamash AM. Evaluation of zeolite A for the sorptive removal of $\mathrm{Cs}^{+}$and $\mathrm{Sr}^{2+}$ ions from aqueous solutions using batch and fixed bed column operations. J. Hazard. Mater. 2008;151: 432-445.

14. Moreno N, Querol X, Ayora C, Alastuey A. Fernandez-Pereira, Potential environmental applications of pure zeolitic material synthesized from fly ash. J. Environ. Eng. 2001;127:994-1002.

15. Novembre D, Sabatino B, Gimeno D, Garcia-Vallès $M$, Martínez-Manent S, Synthesis of $\mathrm{Na}-\mathrm{X}$ zeolites from tripola- ceous deposits (Crotone, Italy) and volcanic zeolitised rocks (Vico volcano, Italy). Micropor. Mesopor. Mater. 2004;75:1-11.

16. Jeon BE, Ahn BJ, Chang WH, Kam SK, Lee MG. Zeolitic conversion of cheju scoria. J. Ind. Eng. Chem. 2004;10:618-622.

17. Barakat MA. Adsorption of heavy metals from aqueous solutions on synthetic zeolite. Res. J. Environ. Sci. 2008;2:13-22.

18. Faghihian H, Godazandeha N. Synthesis of nanocrystalline zeolite Y from bentonite. J. Porous Mater. 2009;16:331-335.

19. Chaisena A, Rangsriwatananon K, Synthesis of sodium zeolites from natural and modified diatomite. Mater. Lett. 2005;59: 1474-1479.

20. Ismail MA, Eltayeb MAZ, Abdel Maged SA. Synthesis of zeolite A from Sudanese montmorillonite clay to remove nickel and copper ions from aqueous solutions. Int. J. Chem. Biochem. Sci. 2013;4:46-56.

21. Lee CH, Park JM, Lee MG. Adsorption characteristics of Sr(II) and $\mathrm{Cs}(\mathrm{I})$ ions by zeolite synthesized from coal fly ash. J. Environ. Sci. Int. 2014;23:1987-1998.

22. Kam SK, Hyun SS, Lee MG. Removal of divalent heavy metal ions by Na-P1 synthesized from Jeju Scoria. J. Environ. Sci. Int. 2011;20:1337-1345.

23. Prelot B, Araïssi M, Gras P, Marchandeau F, Zajac J. Contribution of calorimetry to the understanding of competitive adsorption of calcium, strontium, barium, and cadmium onto 4A type zeolite from two metal aqueous solutions. Thermochim. Acta 2018;664:39-47.

24. Lee MG, Park JW, Kam SK, Lee CH. Synthesis of Na-A zeolite from Jeju Island scoria using fusion/hydrothermal method. Chemosphere 2018;207:203-208.

25. Treacy MMJ, Higgins JB. Collection of simulated XRD powder patterns for zeolites. Elsevier:Amsterdam; 2001.

26. Tanaka H, Fujii A, Fujimoto S, Tanaka Y. Microwave-assisted two-step process for the synthesis of a single-phase Na-A zeolite from coal fly ash. Adv. Powd. Tech. 2008;19:83-94.

27. Hamed MM, Holiel M, Ahmed IM. Sorption behavior of cesium, cobalt and europium radionuclides onto hydroxyl magnesium silicate. Radiochim. Acta 2016;104:873-890.

28. Fuller AJ, Shaw S, Peacock CL, Trivedi D, Burke IT. EXAFS Study of Sr sorption to illite, goethite, chlorite, and mixed sediment under hyperalkaline conditions, Langmuir. 2016;32: 2937-2946

29. Rao GPC, Satyaveni S, Ramesh A, Seshaiah K, Murthy KSN, Choudary NV. Sorption of cadium and zinc from aqueous solutions by zeolite $4 \mathrm{~A}$, zeolite $13 \mathrm{X}$ and bentonite. J. Environ. Manag. 2006;81:265-272.

30. Trogo M, Peri J. Interaction of the zeolite tuff with Zn-containing simulated pollutant solutions. J. Colliod. Interface Sci. 2003;260:166-175.

31. Alemayehu E, Thiele-Bruhn S, Lennartz B, Adsorption behaviour of $\mathrm{Cr}$ (VI) onto macro and micro-vesicular volcanic rocks from water. Sep. Purif. Technol. 2011;78:55-61.

32. Langmuir I. The adsorption of gases on plane surface of glass, mica and platinum. J. Am. Chem. Soc. 1918;40:1361-1403.

33. Freundlich HMF. Over the adsorption in solution. J. Phys. Chem. 1906;57:385-470.

34. Dubinin MM. The potential theory of adsorption of gases and vapors for adsorbents with energetically non-uniform surface. 
Chem. Rev. 1960;60:235-266.

35. Helfferich F. Ion Exchange, McGraw-Hill:New York;1962.

36. Abusafa A, Yücel H. Removal of 137Cs from aqueous solutions using different cationic forms of a natural zeolite: clinoptilolite. Sep. Purif. Technol. 2002;28:103-116.

37. Sekomo CB, Rousseau DP, Lens PN. Use of Gisenyi volcanic rock for adsorptive removal of $\mathrm{Cd}$ (II), $\mathrm{Cu}$ (II), $\mathrm{Pb}$ (II), and $\mathrm{Zn}$ (II) from wastewater. Water Air Soil Pollut. 2012;223:533-547.

38. Kwon JS, Yun ST, Kim SO, Mayer B, Hutcheon I. Sorption of $\mathrm{Zn}$ (II) in aqueous solutions by scoria. Chemosphere 2005;60:1416-1426.

39. Kwon JS, Yun ST, Lee JH, Kim SO, Jo HY. Removal of divalent heavy metals (Cd, $\mathrm{Cu}, \mathrm{Pb}$, and $\mathrm{Zn}$ ) and arsenic (III) from aqueous solutions using scoria: kinetics and equilibria of sorption. $J$. Hazard. Mater. 2010;174:307-313.

40. Kam SK, Hyun SS, Lee MG. Adsorption characteristics of copper and lead ions by Jeju scoria. J. Environ. Sci. Int. 2002;24:57-69.

41. Khan SA, Rehman R, Khan MA. Sorption of strontium on bentonite. Waste Manage. 1995;15:641-650.

42. Galamboš M, Kufčáková J, Rosskopfová O, Rajec P. Adsorption of cesium and strontium on natrified bentonites. J. Radio. Nuclear Chem. 2010;283:803-813.

43. Awual MR, Hasan MM, Shahat A. Functionalized novel mesoporous adsorbent for selective lead(II) ions monitoring and removal from wastewater. Sens Actuators B Chem. 2014;203: 854-863.

44. Ho YS. Isotherms for the sorption of lead onto peat: comparison of linear and non-linear methods. Pol. J. Environ. Stud. 2006; 15:81-86

45. Baek W, Ha S, Hong S, Kim S, Kim Y. Cation exchange of cesium and cation selectivity of natural zeolites: Chabazite, stilbite, and heulandite. Micropor. Mesopor. Mat. 2018;264: 159-166.

46. Choi JH, Lee $\mathrm{CH}$. Adsorption and desorption characteristics of Sr, Cs, and Na ions with Na-A zeolite synthesized from coal fly ash in low-alkali condition. J. Environ. Sci. Int. 2019;28:561-570.

47. Panayotova MI. Kinetics and thermodynamics of copper ions removal from wastewater by use of zeolite. Waste Manage. 2001;21:671-676. 